\title{
Empirical Comparative Evidence from the Consumption Behavior of College Students in China
}

\author{
Xinxin $\mathrm{Wu}^{1,} \mathrm{a}^{\text {* }}$ \\ ${ }^{1}$ Shanghai University, No.99 Shangda Road, Baoshan District, Shanghai, China \\ awuxinxinbozhou@foxmail.com
}

\begin{abstract}
Keywords: Consumer Identity; Identity and Construction; College Students Consumption Behavior; Quantile Regression; Consumer Education Strategy
\end{abstract}

\begin{abstract}
Consumer behavior continuously derives the social function of constructing identity. There has been extensively studied on consumer behavior from the perspective of the sociology and psychology literature, but few on how to construct social identity, the impact on the consumer decision-making, and the lack of practical research on consumption and identity construction which focus on a particular group. In this paper, the young college students of self identity, family responsibility and social expectations are regarded as the research objects which live in the dual environment of "free family" and "constructed society". The consumption is regarded as part of its identity construction, that is, through the design of consumer psychological observation scale and actual investigation to make a intensive study about the harmful consumption behavior of college students who hope to construct identity relying on consumer identity. In order to grasp the influence of consumer identity on the consumption behavior of college students in different regions, Increase the stability and reliability of the model, and clarify the overall effect of consumer identity on consumer behavior, this paper introduces the bootstrap quantile regression technology, and makes a comparative analysis of the two groups of survey data between Shanghai and Anhui college students. Research findings: First, the tendency of self identity construction leads to high confusion between the students in both consumption level and the proportion of image consumption; Second, based on the sense of belonging, group consumption behavior has obvious characteristics of mean level, and the phenomenon of "herd effect", which increases human consumption in order to obtain group identity, is widespread. Third, the boundary effect of group boundary in Anhui and Shanghai samples, which shows the rise of the proportion of image consumption and social consumption respectively.
\end{abstract}

\section{Introduction}

According to the 2016 China Statistical Yearbook, the number of ordinary college graduates in China has increased year by year. In 2015, the number of young people in the school increased by 26.253 million. The rising proportion of young people with higher education qualifications indicates that China's higher education model is gradually becoming more elite. The transition to mass education. The social superiority of traditional higher education has gradually declined. It is in the group of college students who are constantly evolving and eager to show their self. They are eager to seek a new means or means to represent and construct their own identity. College students' consumption behavior is no longer just a simple item consumption, but also an important manifestation of its labeling expression self and identity construction. Influenced by consumerism, the group began to seek the avant-garde of consumption to show their youthful vitality, trying to show their existence to the society with a new consumer image. Some college students regard consumption as a status symbol, lose their identity in the pursuit of fashion, lose themselves in consumption, and easily become marginalized in the state of dissatisfaction. The contemporary consumption pattern of college students not only represents the mainstream and direction of future consumption, but also affects the entire social consumption culture and industry. Therefore, profound understanding and grasping the theoretical roots behind its consumption behavior, re-shaping the identity of college students through the guidance of consumer education and 
consumption concepts is an important practical problem that universities and even the whole society urgently need to face.

In order to further characterize the characteristics of college students' consumption psychology and demonstrate its influence on consumer behavior and its impact mechanism, the main purposes and contributions of this study are as follows: First, theoretical research, the "conscious theory" in the sociological classic "consumer identity" On the basis of "group theory" and "interaction theory", it integrates the theory of identity economics and research results, and combines empirical analysis to portray the consumption psychology and consumption behavior of college students. The research forms the theoretical framework of consumer identity, and depicts the consumption psychology of college students based on the three dimensions of self-identification, attribution and hierarchy identification. Secondly, it not only pays attention to the consumption characteristics and consumption psychology of college students, but also pays more attention to the research on the influence of consumer identity on consumer decision-making, so as to systematically and clearly demonstrate the influence mechanism of consumer identity psychology on consumer behavior under the background of identity construction. The third is to better highlight the impact of the external environment on consumer identity, introduce the technical means of repeated sampling quantile regression and compare and analyze the two groups of research data of Shanghai and Anhui college students, and more carefully grasp the consumer identification variables for colleges and universities. The difference in the intensity of the student's consumption behavior increases the stability and reliability of the model. The identity and construction of college students affect their consumption behavior, which in turn affects the sense of well-being and human capital accumulation, and even affects the entire social consumption culture. The research has important reference value for establishing a correct view of college students' consumption, reshaping the sense of identity of college students and increasing the accumulation of human capital through consumption concepts.

The rest of the paper is organized as follows: the second part is literature review, the third part is the Hypothesis and Reliability test of consumer identity, further is to construct the consumption psychology index of college students and finally empirically analyze the effect of the three dimensions of consumer identity on consumer behavior.

\section{Literature Review}

Akerlof and Kranton introduced identity to the neoclassical analysis framework and pioneered Identity Economics [1-3]. The study defines identity as a self-perception associated with a particular social category, primarily examining the impact of identity on individual behavior and the behavior of its group. After the introduction of the identity factor, the personal utility is maximized through external consumption. In addition to considering the individual's own behavior, the influence of others in the group and the self-identity in the group should be examined. Li Shujuan and $\mathrm{Xu}$ Xianxiang believe that Akerlof's identity hypothesis aims to internalize identity attributes and reveal the influence of identity on human behavior and performance under the framework of neoclassical economics. However, in the specific analysis, it believes that many identities are endogenous to some extent. Therefore, only the exogenous influences such as gender and ethnicity were examined in detail [4]. Subsequently, Amartya Sen further promoted the development of the theory and elaborated on identity selection. He emphasized that people's identities are multiple. In different affiliations and social relationships, people are constantly deciding which identities are given priority, and the relative importance of an identity depends on personal characteristics and social environment [5]. The personal characteristics, social environment and multiple identity characteristics of the identity emphasized by the theory correspond exactly to the aforementioned conscious theory, group theory and interaction theory.

This study regards consumption as part of the construction of college students' identity, that is, from the fact that college students are separated from the original family and begin to build their own identity, so that the group is eager to seek a means and means to maintain and construct their own identity. The scale is an in-depth study of the desire of college students to carry out identity 
construction through consumer identity behind the bad consumer behavior. In order to further clarify the effect of consumer identity on consumer behavior, this paper introduces the technical means of repeated sampling quantile regression and conducts a comparative analysis of the survey data of Shanghai college students and Anhui college students in order to grasp the consumer identification variables more carefully. The difference in the intensity of the consumption behavior of college students in different regions increases the stability and reliability of the model.

\section{Hypothesis and Reliability Test}

\section{Hypothesis.}

Hypothesis 1: Self-identity affects vanity consumption behavior. That is to realize the characteristics of being different from others or groups by pursuing individualized consumption methods, and to clarify one's unique identity through the alienation of other people's consumption behaviors, so as to realize identity construction and maintenance. Corresponding to the RT1, RT2, and RT3 variables in the approval scale (see Table 1).

Hypothesis 2: Ownership affects the behavior of hereditary consumption. That is to say, psychologically seeking the psychological sensibility of the identity of the group by means of the same way. Individuals are trying to clarify their group identity through the integration of internal groups and the representation of external groups because they are worried that their status is not recognized by others. Correspond to the RT4, RT5, and RT6 variables in the approval scale (see Table 1).

Hypothesis 3: The sense of class division affects exemplary consumption behavior. That is to say, through the exemplary consumption behavior to strengthen or break through the boundary of different groups to satisfy the psychological security, it is the subjective cognition and judgment of the social class in the process of differential labeling of consumer behavior. Corresponding to the RT7, RT8, and RT9 variables in the approval scale (see Table 1).

Table 1 Consumer Identity Measurement Table

\begin{tabular}{|c|c|c|c|c|c|c|}
\hline Assumptions & $\begin{array}{l}\text { Question } \\
\text { number }\end{array}$ & View & $\begin{array}{l}\text { Strongly } \\
\text { Agree }\end{array}$ & Agree & $\begin{array}{l}\text { Not quite } \\
\text { agree }\end{array}$ & $\begin{array}{l}\text { Very } \\
\text { disagree }\end{array}$ \\
\hline \multirow{3}{*}{$\begin{array}{l}\text { Self-identity } \\
\text { hypothesis }\end{array}$} & $R T 1$ & $\begin{array}{l}\text { Consumption should be consistent } \\
\text { with the identity of their college } \\
\text { students }\end{array}$ & - & - & - & - \\
\hline & $R T 2$ & $\begin{array}{l}\text { The character and taste can be } \\
\text { judged by the goods owned by one } \\
\text { person. }\end{array}$ & - & - & - & - \\
\hline & $R T 3$ & $\begin{array}{l}\text { I pay more attention to brand and } \\
\text { personality when buying goods } \\
\text { under economic conditions. }\end{array}$ & - & - & - & - \\
\hline \multirow{3}{*}{$\begin{array}{l}\text { Attribution } \\
\text { identity } \\
\text { hypothesis }\end{array}$} & $R T 4$ & $\begin{array}{l}\text { I prefer to be friends with } \\
\text { classmates with similar family } \\
\text { conditions. }\end{array}$ & - & - & - & - \\
\hline & $R T 5$ & $\begin{array}{l}\text { People with the same taste of food } \\
\text { are more likely to be friends }\end{array}$ & - & - & - & - \\
\hline & RT6 & $\begin{array}{l}\text { Sometimes } \quad \text { adjust their } \\
\text { consumption } \\
\text { "group" }\end{array}$ & - & - & - & - \\
\hline \multirow{3}{*}{$\begin{array}{l}\text { Distinguishing } \\
\text { identity } \\
\text { hypothesis }\end{array}$} & $R T 7$ & $\begin{array}{l}\text { The more famous brands, the more } \\
\text { face they have. }\end{array}$ & - & - & - & - \\
\hline & $R T 8$ & $\begin{array}{l}\text { I used to save money in order to } \\
\text { buy brand-name goods. }\end{array}$ & - & - & - & - \\
\hline & RT9 & $\begin{array}{l}\text { If you have money, buy some } \\
\text { brand-name goods and let the } \\
\text { students look at them. }\end{array}$ & - & - & - & - \\
\hline
\end{tabular}




\section{Reliability test.}

In order to test the stability of the actual survey results of the measurement scale, this study used the inherent consistency $\alpha$ coefficient and the non-parametric Friedman test to verify the reliability of the two samples of the evaluation scale. The results show that the Cronbach's Alpha coefficients of Shanghai's consumer recognition quota, self-identity, belonging identity and class distinction are 0.725, 0.802, 0.634 and 0.786 respectively; Anhui Province's consumer recognition total scale, self-identity Cronbach's Alpha coefficients, belonging identity and class distinction are 0.782, $0.590,0.650$ and 0.839 , respectively. Both dimensions and the total scale of the two samples reached a credible level. The chi-square observations of the overall Friedman average rank test of the two-sample scale are 127.913 (Shanghai) and 266.406 (Anhui), and the corresponding probability $\mathrm{P}$ values are all 0 . It is considered that there is a significant difference in the mean value of each item. The evaluation system is able to distinguish between evaluators on both samples.

\section{Model Construction and Result Analysis}

\section{Data source.}

In the Shanghai area, 300 questionnaires were distributed and 292 were collected, of which 234 were valid questionnaires, and the effective recovery rate was $80.14 \%$. 406 questionnaires were distributed in Anhui colleges and universities, 400 were collected, of which 382 were valid questionnaires. The rate was $94.6 \%$. The study used random sampling to take random sampling within the school, taking into account the type of school. The final sample of the survey involved 15 different types of institutions such as "985", " 211 " and general undergraduate, with certain representativeness.

\section{Interpreted variables.}

Consumer behavior mainly includes two indicators: consumption level and consumption structure.

The level of consumption is "the total monthly expenditure of college students". According to the survey, the average consumption expenditure of college students in Shanghai is 1,670 yuan, and the average monthly expenditure of some students is as high as 4,700 yuan, nearly three times higher than the average; the average consumption expenditure of college students in Anhui Province is 1,185 yuan, and the monthly average of some students Expenditure reached 2,600 yuan, more than twice the average .

The consumption structure includes "image consumption and social consumption ratio" as indicator variables of the consumption structure. Image consumption is an important manifestation of college students' self-perception. Social consumption is the main form of college students' sense of belonging, which affects the social capital accumulation of college students to some extent. Among them, college students' image consumption accounted for nearly $20 \%$ on average, and social consumption accounted for an average of $15 \%$.

\section{Explain the variables.}

\section{Key explanatory variables}

According to the above evaluation system of consumer identity metrics, factor analysis of college students' consumer identity variables in two samples:

On the basis of principal component analysis, three common factors are extracted, and the orthogonal transformation is performed on the factor load matrix using the maximum variance method to make the factors have naming explanatory. According to the factor extraction results, three comprehensive factors (Fig. 1) can be obtained and named (Table 2). The extracted factors are in good agreement with the original hypothesis, and RT6 is divided into the interval variable. . 


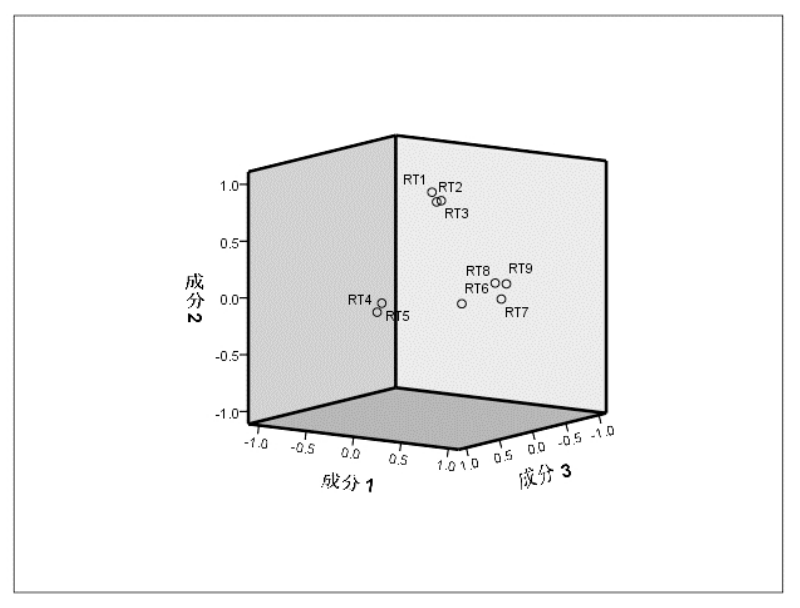

Figure 1 Component Load in Rotating Space

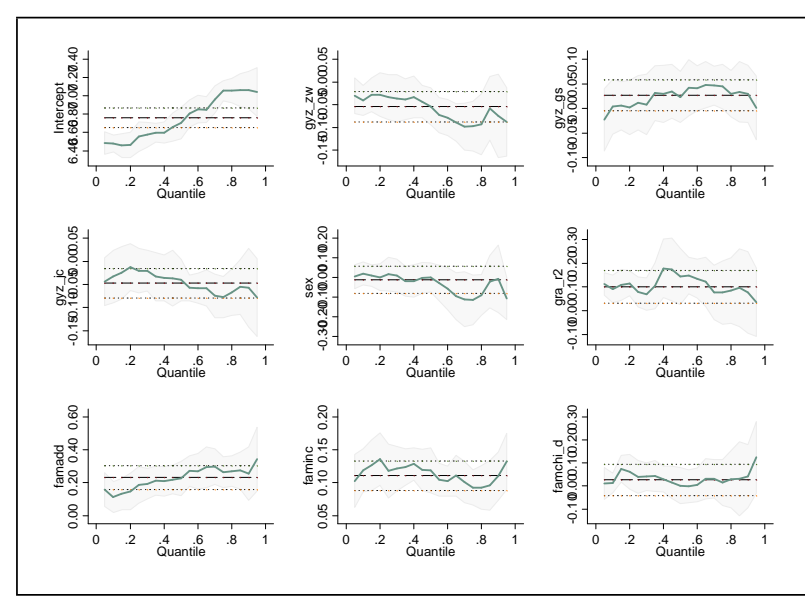

Figure 2 Quantile Regression Results I

Table 2 Factor extraction and naming

\begin{tabular}{ccc}
\hline Factor source & Observation variable & Factor naming \\
\hline Common factor 2 & $R T 1, R T 2 、 R T 3$ & Self-identity \\
Common factor 3 & $R T 4 、 R T 5$ & Self-Ownership \\
Common factor 1 & $R T 6 、 R T 7 、 R T 8 、 R T 9$ & Self-Class division \\
\hline
\end{tabular}

Hierarchical disparity variables (male factor 1), self-identification variables (male factor 2), and belonging identity variables (common factor 3 ) are the key variables of consumer identity studied in this paper.

\section{Control variables}

First, the respondent's personality characteristics, including gender, grade variables. Second, family characteristics, including the living environment, the total annual income of the family, and the number of children in the family. Other variables such as professional and parental occupational backgrounds were excluded because the categories were scattered and the level of significance was low. According to Table 4, taking Shanghai university data as an example, the proportion of women in the sample is $60.34 \%$, the proportion of graduate students is $31.90 \%$, the proportion of the family in the city is $54.31 \%$, and the total annual income of the family is in the fourth interval, that is, 60,000 to 90,000 . The number of children in the family averages between one and two.

\section{Equations.}

In order to observe the different degrees of consumption identity variables at different quantiles in the distribution of consumer behavior, a group-based bootstrapped repetitive sampling quantile regression method was used to estimate the impact of three college students' consumer identity dimensions on consumer behavior. The purpose of sample grouping is: first, the provincial variables are only the control variables of the study, not the key variables. Second, because the sample values in different regions are significantly different, the mixed data is easy to cover the different sample features. Third, it is easy to compare after grouping. The difference in the impact of different sample college students' consumption identity on consumer behavior; Fourth, the two-sample comparative experiment after grouping will further improve the test intensity of model stability. The basic idea of quantile regression analysis was proposed by Koenker \& Bassett (1978) as an extension of the ordinary least squares estimate (OLS) [6]. Compared with the least squares estimation, its advantages are mainly: one is different from the effect of estimating the independent variable on the conditional mean of the dependent variable in the least squares method, and the estimated parameter in the quantile regression model will be different with the different distribution 
of the dependent variable. The change is more conducive to a more detailed and comprehensive analysis of the research object. Second, the estimation result is more stable, and the model does not make specific assumptions about the error term distribution. Therefore, it has a non-normal distribution or outlier value of the survey data. High fault tolerance. Regarding the bootstrap type quantile regression, this method was first introduced by Efron (1979) [7], which is different from the general Monte Carlo simulation method, which is assumed to have a general distribution. In the sampling method, the sample of size $\mathrm{n}$ is taken, and each resampled sample randomly deviates from the initial sample. Therefore, the method can overcome the small number of observation samples while ensuring the stability of the model output.

Based on the above variables, the following quantile regression model was established:

$$
\operatorname{Quant}_{\left(Y_{v_{i}} \mid X_{i, j}\right)}=\alpha_{0}^{(q)}+\alpha_{1}^{(q)} X_{1 i}+\alpha_{2}^{(q)} X_{2 j}+\varepsilon_{i}^{(q)}
$$

$Y_{v i}$ is the consumption behavior, $v=1$ : the consumption level variable (the total monthly expenditure of the university students processed by logarithm); $v=2$ : the consumption structure variable (the proportion of image consumption expenditure and the proportion of social consumption expenditure).

$X_{1 i}$ is the key variable of consumer identity, and is the result of factor analysis of the above consumer identity variables, including $i=1$ : hierarchical disparity variable (male factor 1 ); $i=2$ : self-identification variable (common factor 2); $i=3$ : Affiliation identification variable (common factor 3).

$X_{2 j}$ is a control variable that controls variables that mainly include "resident personality characteristics" and "native family characteristics" that may affect college students' consumption behavior.

\section{Summary}

"Vanity effect" and "Climb effect" under self-identity.

There is a significant positive correlation between self-identity and consumer spending and image consumption. That is, the stronger the personality of the students, the higher the proportion of consumer spending and image consumption. Specifically, on the one hand, in the quantile coefficient map, the self-identity coefficient of Shanghai sample data is tilted to the lower right, while the self-identity coefficient of Anhui sample data shows a narrow range of fluctuations in the middle mean, indicating students in Shanghai area. Based on self-identity, vanity consumption behavior is more significant, and labeling identity construction is more prominent. On the other hand, as the grading point rises, the absolute coefficient of self-identification variable also increases, indicating high expenditure and high expenditure. In the group, the consumption self-identity has a more significant impact on the extreme consumption behavior.

Students who pursue individuality and self-fulfillment, in order to satisfy the avant-garde vanity, hope to maintain the personalized label-based identity construction and gain satisfaction with this way of high consumption, which relies on avant-garde consumption to establish a unique identity. Motivation is the root cause of college students' consumption vanity and labeling behavior. Students who are pursuing individuality are more inclined to package themselves through image consumption, in order to demonstrate their unconventional life.

"Congregational effect" under the sense of belonging.

Attributive identity has a significant effect on the average level of consumer spending, and has a significant positive correlation with the proportion of social consumption. That is to say, overall, the stronger the sense of belonging identity, the consumption expenditure has a significant trending mean feature, accompanied by a high intensity of social consumption. Specifically, in the sample of Shanghai, the coefficient of attributional identity variable showed a first increase and then decrease with the consumption level above zero, and reached a negative correlation peak near the 0.6 quantile, indicating that the attributional identity variable was "average" in consumer expenditure. The effect at the level is most significant. However, in the group of high consumption expenditure levels, this negative inhibition (decreased coefficient of attribution identity variable) is gradually 
reduced, and polarization does exist. In the Anhui sample, the attribution identity is inclined to the lower right and is 0.5. Crossing the zero line near the quintile indicates that the consumer sense of belonging has a positive effect on the level of consumption expenditure among the student groups below the average consumption level, while in the student group above the average consumption level, the sense of belonging to the consumer The negative impact on the level of consumer spending, the trend of consumption in Anhui is more prominent.

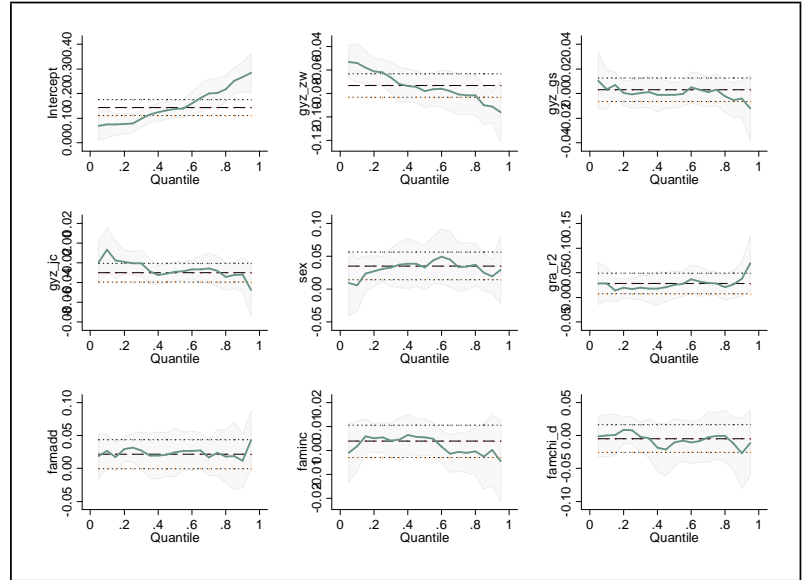

Figure 3 Quantile Regression Result II

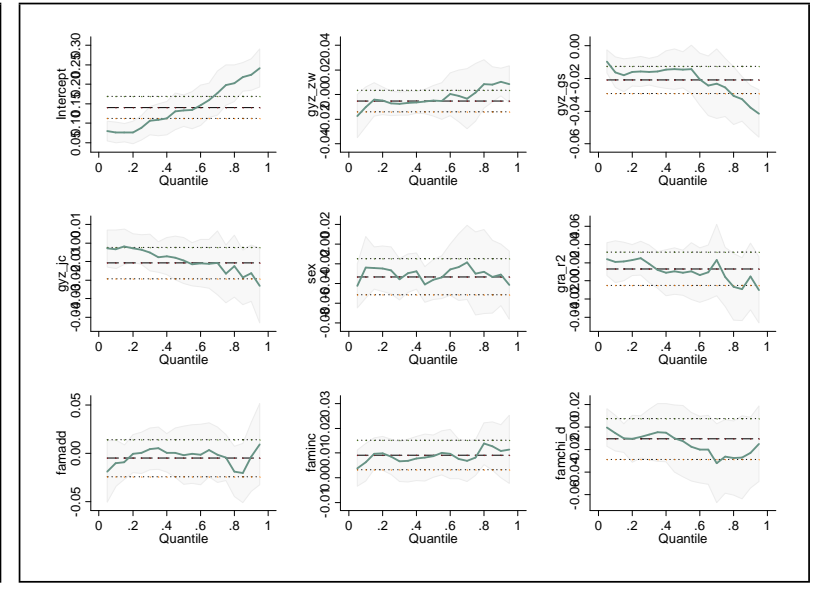

Figure 4 Quantile Regression Result III

\section{References}

[1] George Akerlof, Rachel Kranton. Economics and Identity [J]. Quarterly Journal of Economics, 2000,115(3),715-753.

[2] George Akerlof, Rachel Kranton. Identity and Schooling some Lessons for The Economics of Education[J]. Journal of Economic Literature,2002,40(4),1167-1201.

[3] George Akerlof, Rachel Kranton. Identity Economics[M]. Princeton: Princeton University Press, 2010.

[4] Li Shujuan, Xu Xianxiang. Identity and Economic Growth [J]. Economics (Quarterly), 2016, (03): 941-962.

[5] Sen Amartya. Identity and Violence: The Illusion of Destiny. [M]. New York: W.W. Norton \& Co, 2006

[6] Koenker R, Bassett G W. Regression quantiles [J]. Journal of Economic Perpectives,1978 (15):33-50.

[7] Efron, B. Bootstrap methods: Another look at the jackknife [J]. Annals of Statistics,1979 (7):1-26. 